\title{
Discussion on the Teaching Reform of CDIO and Intelligent Car Competition
}

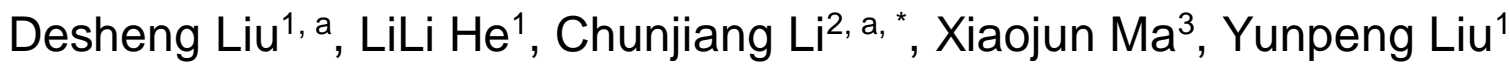 \\ ${ }^{1}$ School of Information and electronic technology, Jiamusi University, Jiamusi, 154007, China; \\ 2Dean's office, Jiamusi University, Jiamusi, 154007, China; \\ ${ }^{3}$ School of Mechanical Engineering Jiamusi University, jiamusi, 154007, China. \\ ajmslcj@sohu.com
}

\begin{abstract}
In order to improve the students' ability of innovation and practice, the CDIO education idea and the smart car competition content are combined, some problems in the teaching reform program was analyzed, put forward "automatic control principle" course, we increase the experimental contents, and the project of education reform in accordance with the training of Engineers.
\end{abstract}

Keywords: CDIO, Intelligent Car Competition, Teaching Reform.

\section{Introduction}

The CDIO education mode is the newest achievement of new century international engineering education reform, it is a kind of engineering education reform mode by the Massachusetts Institute of Technology Sweden Chalmers Industrial University, Huang Zhong Institute of technology and Linkoping University in 2000 by a guide, CDIO are Conceive (concept), Design (Design), Implement (Implementation), Operate the first letter (operation). The core of this concept requires that the engineer's personal, interpersonal, and system building capabilities must be achieved in the real engineering practice environment and in the solution of engineering problems. In 2005, there are more than and 30 colleges and universities in our country to join the ranks of the CDIO education model, and most of the electrical and mechanical major, in the continuous exploration has also achieved initial results [1]. It can be seen that the reform of higher education in China is in line with international practice.

Freescale smart car competition in the Carle model car platform on the regulations, the use of Free scale Semiconductor Inc 8 bit and 16 bit microcontroller as the core control module, by increasing the road sensor, motor drive circuit and write the corresponding software, making an independent recognition of road model cars, in accordance with the provisions of the route, the time to complete short for the winners of [2]. Is covered by the control, pattern recognition, sensor technology, electronics, electrical, computer, machinery and other disciplines of the game. The contest began in 2006, has been held 11 sessions, has developed into more than 30 provinces and autonomous regions in the country more than 170 colleges and universities to participate in the National Smart car contest. Competition is an important carrier and an effective way to cultivate innovative thinking and cultivate innovation ability, but also the process of understanding and solving problems in practice, which is in line with CDIO's educational philosophy. The combination of the two can cultivate students' engineering ability in practice.

\section{Intelligent Car Competition and Curriculum Links}

"Automatic control principle" is the main course of automation specialty, it is learning the "modern control theory", "process control" and other undergraduate follow-up courses, learning is "linear system theory", "adaptive control" and other graduate courses or industrial foundation, [3] theoretical basis for process control and optimization design. Independent set up "theory, experiment, and curriculum design". In order to cultivate the students' professional knowledge and practice ability in the course of experiment, the students' ability of system analysis and engineering application. These three aspects together, to a certain extent, cultivate the abilities to analyze problems of students, but 
due to experimental aging equipment, experiment content, curing comprehensive and innovative practice teaching is relatively weak, it is still difficult to achieve satisfactory teaching effect, cannot meet the current social development of talent training requirements.

Competition involves more professional knowledge, can be a good training of College Students' knowledge integration and mining capabilities, as well as a strong sense of initiative and innovation, truth-seeking and pragmatic style of study and team spirit of cooperation.

\section{Problems in Teaching}

This course features: theory, engineering application background is more direct, timely in the study of theory is introduced, the students will think that the early contact between theory and practice, cannot achieve the abstracted engineering problems; and the theories related to the knowledge more, general engineering courses in the row then, circuit, analog and digital circuit, and to have a solid professional basis, there is a strong mathematical foundation, because in the course of running through calculus, complex transformation and matrix of knowledge. In the experiment, the experimental content for the confirmatory test, experimental platform and experimental content of aging, cannot meet the requirements of cultivating practical and innovative abilities of students, students in the process of experiment on experimental guide books, the lack of active learning and exploring knowledge and teamwork spirit. These problems are common in engineering teaching.

Therefore, in order to cultivate students' innovative practice and team comprehensive engineering ability, improve the students' interest and participation level subject contest, we will consider the knowledge of intelligent competition into the "automatic control" in the teaching reform, the completion of the project to start learning from the selection, design, data analysis, modeling, simulation, experiment report full cycle.

\section{Teaching Reform Based on CDIO and Competition}

The principle of automatic control course reform from the six main parts of the engineering education theory and practice CDIO standard; smart car contest topic analysis, project planning and design and knowledge extraction, teaching system, teaching resources reorganization and optimization of network implementation.

\subsection{The Core Idea of CDIO Engineering Education}

CDIO said two of the most fundamental problems in engineering education, namely, what kind of training people how to cultivate people's problems in the culture of what people on the issue of "reform made a total of three goals in the" how to train people "" the implementation methods of the educational theory of constructivism "and through 12 standard guidelines for engineering education reform. Facing the problems of the development of engineering education and the development of science, technology, industry and engineering practice, this paper puts forward the integrated solution [4,5]. Therefore, we should draw lessons from the core educational idea of CDIO, and set up the reform scheme of automatic control theory course from four aspects, such as training content, course system, teaching method and evaluation improvement.

Table 1. Integrated curriculum reform program

\begin{tabular}{|c|c|c|c|}
\hline Training conten & curriculum system & teaching method & Evaluation improvement \\
\hline $\begin{array}{l}\text { Into the smart car race } \\
\text { content }\end{array}$ & $\begin{array}{c}\text { Enhanced } \\
\text { backbone course }\end{array}$ & $\begin{array}{l}\text { Competition driving } \\
\text { Project driven }\end{array}$ & $\begin{array}{l}\text { Complete all phases of } \\
\text { the proiect }\end{array}$ \\
\hline Strengthening & Open intelligent & Inquiry Teaching & Omnibearing \\
\hline practice & vehicle elective & Discussion Teaching & stereoscopic \\
\hline \multirow{4}{*}{$\begin{array}{l}\text { Reduce disciplinary } \\
\text { boundaries }\end{array}$} & course & & examination \\
\hline & Increase & & Student participation \\
\hline & simulation & & \\
\hline & experiment & & \\
\hline
\end{tabular}




\subsection{Intelligent Car Competition Content Analysis}

The main content of the competition is composed of the function modules such as path identification, angle control and speed control. Involved in more courses, including: $\mathrm{C}$ language programming, computer principles and applications, analog electronic technology, testing technology and automation instrumentation, computer control technology, and other courses.

In the course of automatic control principles involved in the knowledge points are: PID control algorithm, fuzzy control algorithm, system stability analysis, etc.

\section{3 project Planning And Design And Knowledge Extraction}

Combined with the CDIO theory and the content of the smart car competition, in order to solve the problems faced by the current practice teaching to increase the comprehensive design of the project, the name of the project and the knowledge involved in the contest is as follows Table 2.

Table 2. Project Planning

\begin{tabular}{ll}
\hline CDIO Project & Knowledge points involved in competition \\
\hline Design of DC motor speed control system & Fuzzy PID controller design \\
Design of DC motor control system based on & PID controller parameter tuning \\
PID control & Implementation of digital PID controller \\
Steering servo control system design & Design and application of fuzzy controller
\end{tabular}

\section{4 optimization of curriculum system}

According to the CDIO project planning ahead, according to the project solution, the entire project will be split into several sub projects, corresponding to the contest involves knowledge points, and further corresponding to the theoretical knowledge, the curriculum for example, in the design of DC motor control system PID control, can be divided into: design and parameters of the motor control system setting and simulation experiment of two sub projects, projects can be divided into several small tasks assigned to each member of the group. The order of the project should be corresponding to the theoretical course, so that the theory is consistent with practice. In most colleges and universities are the theory and practice of curriculum design - the three steps to complete the whole course of the teaching, but the proportion and time setting, different professional requirements, automation professional, theory and practice should be with both hands, both hands; and should be from the first grade through competition the idea of arousing the students' interest, has penetrated into professional knowledge, professional elective courses to increase the charm of smart car competition, strengthen the software engineering talents training in accordance with the process of learning, from the professional amateur.

\section{5 the implementation of network teaching resources}

The teaching platform is divided into three modules: teaching module, student module and forum. The teaching module can upload the term with the teaching syllabus, curriculum PPT, evaluation criteria, evaluation index, smart car competition content; the student module, you can upload video works, operation is convenient for teachers, teachers and students can enjoy the forum discussion about all the problems of control, in order to facilitate students' Autonomous learning.

\section{Conclusion}

Based on the teaching concept of CDIO, the construction of intelligent vehicle competition and the course of "automatic control theory", this paper expounds the close relationship between the three, and preliminarily establishes the content and direction of the reform. Guided by the advanced teaching idea, the teaching reform will be greatly improved, which is worthy of popularization and popularization.

\section{Acknowledgments}

This work was supported in part by Jiamusi University education and teaching research (No. JYZL2015-05) and Heilongjiang higher education reform project (No. JG2014011046). 


\section{References}

[1]. Gu Peihua, Bao Nengsheng, Kang Quanli.CDI0 in China (on [J]), the research of higher engineering education, 2012 (03): 24-40.

[2]. Richard C D, Robert B. Control System (10th Edition) [M]. Beijing: Science Press, 2007 (in Chinese) $\mathrm{H}$ (in Chinese) Modern

[3]. Zuohua Tian, Chen Xuezhong, Weng ZhengXin. Control engineering foundation [M]. Beijing: Tsinghua University press, 2007

[4] Lu Huijuan, Xie Xun, Zhao Shijing, et al. Discussion on the teaching reform of the course of automobile structure and principle based on CDIO education theory [J]. science and technology information, 2012 (32): 19-19.

[5]. Zhang Rugen. Based on the concept of IPR-CDIO China World Trade Center professional practice teaching reform research $[\mathrm{J}]$. experimental technology and management, 2011, 28 (11):121-123. 